Research, part of a Special Feature on Historical and Future Ranges of Variability

\title{
Is There Potential for the Historical Range of Variability to Guide Conservation Given the Social Range of Variability?
}

\author{
$\underline{\text { Jonathan R. Thompson }}^{1,2}$, Sally L. Duncan ${ }^{2}$, and $\underline{\text {. Norman Johnson }}^{2}$
}

\begin{abstract}
Using the historical range of forest conditions as a reference for managing landscapes has been proposed as a coarse-filter approach to biodiversity conservation. By emulating historical disturbance processes, it is thought that forest management can produce forest composition and structure similar to the conditions that once supported the native biota. A recent project was designed to integrate social and ecological findings to investigate the important relationships between the state of ecological understanding of a region, the state of the region's biodiversity, and the state of the region's social understanding of how it might be managed for biodiversity conservation into the future. The project relied on established concepts of the historical range of variability (HRV) and developed the concept of the social range of variability to help explain the interaction of social and ecological assessments, particularly their interaction to create future ranges of variability. The Oregon Coast Range, where a rich history of HRV research has been completed starting with paleoecological reconstructions of the historical fire regime, was one of five sites in the United States that were selected as case studies. We found land development and impending climate change to be major hurdles impeding the use of the HRV as a management regime. We also found that the complexities and uncertainties of management preclude the use of any single tool to tackle landscape-scale challenges and suggest that land management needs to become a continuous process of negotiation.
\end{abstract}

Key Words: future range of variability; historical range of variability; social acceptance; social range of variability

\section{INTRODUCTION}

The Oregon Coast Range contains some of the most productive conifer forests in the world (Spies et al. 2002). Although most of this two million hectare province remains forested, the contemporary landscape is well outside of any historical precedent in terms of forest structure, especially with regard to the abundance of old forest (Wimberly et al. 2000, Wimberly 2002, Nonaka and Spies 2005). Modern forest structure in the Coast Range is divided along lines of ownership classes and is a mosaic of industrial, nonindustrial private, and public land (Stanfield et al. 2002). If future forest management resembles the recent past, the contrast between private and public land is expected to sharpen further (Nonaka and Spies 2005, Thompson et al. 2006). The biophysical environment offers relatively high potential for the use of the historical range of variability (HRV) as part of a conservation strategy; however, the economic and social situation may make this approach intractable.

This landscape, its ecological history and biodiversity, and its social context formed one of the regional case studies for the Future Range of Variability (FRV) project funded by the National Commission on Science and Sustainable Forestry. The project developed two closely related areas of investigation. The first was a literature-based ecological assessment of historical variability, current land use, biodiversity status, conservation management approaches, and possible future biophysical trends affecting management. The second was a social assessment of current attitudes toward the use of the HRV as a management tool for assessing and planning biodiversity conservation in light of the possible future trends. This was accomplished through the analysis of data gathered from a focus group involving a range of participants attending a half-day workshop in Corvallis, Oregon. The central question we addressed in both assessments was: How do future social and ecological trends affect the usefulness of the HRV concept to manage for biodiversity conservation and sustainable timber harvest?

Traditionally, ecological and social assessments have been designed and executed separately, with no acknowledgement that each is critical to weaving 
a complete tapestry of a region's biodiversity status, potential, and challenges. The historical division between scientists and nonscientists, the allegedly rational and irrational, and decisions made in democratic and technocratic settings all contribute to the propensity to view ecological and sociological information separately (Priest 1995, Pouyat 1999, Fischer 2000, Rykiel 2001, Yosie 2001, Duncan 2006). However, in many senses, ecological and social contexts are co-dependent and even cocreated: unless one pretends that human beings and their daily pursuits do not exist, how humans treat ecosystems and what humans think about the ecosystems are inextricably connected. Social acceptability of landscape conditions and management prescriptions have long been recognized (e.g., Firey 1960, Clawson 1984), but only more recently have been widely acknowledged as a central component of a science-based policy development approach (e.g., Stankey and Shindler 2006).

The FRV project was designed to integrate social and ecological findings, which is not a trivial task, and thus to investigate the important relationships between the state of ecological understanding of a region, the state of a region's biodiversity, and the state of the region's social understanding of how it might be managed for biodiversity conservation into the future.

The project relies on a unified concept of range of variability that is delineated in separate syntheses (S. L. Duncan, B. McComb, and K. N. Johnson unpublished; B. McComb and S. L. Duncan unpublished). The authors relied on established concepts of HRV and developed the concept of the social range of variability (SRV) to help explain the interaction of social and ecological assessments, in particular their interaction to create the FRV. They define each of these concepts as follows. The HRV is the estimated range of some ecological condition that occurred in the past. Historically, this range of variability denotes a dynamic set of boundaries between which most native biodiversity variables have persisted, with fluctuations, through time and across space (Morgan et al. 1994, Aplet and Keeton 1999, Landres et al. 1999, Swetnam et al. 1999). The FRV is the estimated range of some ecological condition that may occur in the future. The SRV is the range of an ecological condition that society finds acceptable at a given time.

\section{BACKGROUND}

The HRV of ecosystem function or composition is often estimated to better understand the bounds around temporally dynamic landscapes. Interest in the HRV reveals an increasing appreciation for the directional and stochastic changes that shaped the ecosystems that we see today. The HRV may be a useful part of a conservation strategy for establishing reference conditions toward which natural resource managers may strive. Almost as often as the HRV conservation approach is suggested, it is dismissed as irrelevant on the grounds that the future has made no promises to look or act like the past. The term FRV is being advanced to describe a modification of the HRV strategy that adjusts for factors that are expected to be different in the future such as climate, human population, social acceptability, and exotic species. Here, we examine the strengths and weaknesses of an HRV approach to conservation. We then summarize the historical ecological research done within the Oregon Coast Range and describe how it has been used to evaluate the current landscape. We analyzed data from a workshop to assess social views on HRV and FRV concepts. Finally, we examine two recent studies that have modeled the future Coast Range in light of what is known about the past.

\section{Historical range of variability as a conservation strategy}

The management of ecosystem components to remain within or close to their HRV has received at least two decades of research and experimentation (e.g., Franklin and Foreman 1987, Hunter 1990, Swanson et al. 1994, Landres et al. 1999). The examination of evidence of the historical range of ecological conditions offers a way to understand the conditions that supported the evolution of native species. The concept assumes that although all ecosystems changed continuously through time, there were limits to the extent and magnitude of the changes. It is further assumed that today's native species are adapted to this range of conditions.

The HRV approach has intuitive appeal. First, it is a coarse-filter approach to conservation, meaning that it focuses on shaping broad habitat conditions so that many species, i.e., large and small, charismatic and obscure, may be conserved simultaneously. Practically speaking, this is a major improvement over species-specific strategies that 
require detailed information on each species, which often does not exist, to conduct viability analyses and formulate protection strategies. It explicitly recognizes the dynamism of ecosystems and the paramount importance of disturbance in structuring ecosystems. This is a giant step away from the "balance of nature" dogma, which dominated early ecological thinking and, consequently, conservation policy.

The scientific understanding of forest ecology has changed fundamentally over the past 30 years; this transition has been referred to as an "ecological revolution" (Botkin 1996). There has been a shift from a linear to a stochastic interpretation of forest development. Until recently, forest development was viewed as balanced and predictable. It was assumed that if a forest were undisturbed, it would proceed predictably along a successional track, eventually reaching a static climax phase where it would remain indefinitely. It was further assumed that this condition was best for the forest and all the associated organisms (Botkin 1992). In contrast, the HRV approach explicitly recognizes that ecosystems change over time through diverse pathways driven by succession and disturbance, which yield important and enduring legacies such as dead wood, soil organic material, and seed banks.

The HRV of forest ecosystem composition, structure, and function is usually invoked for one of two reasons: landscape restoration ecology or emulating natural disturbance regimes with timber harvests. The notion of landscape restoration ecology is typically the focus when forestry is not a dominant part of the economy and when fire suppression or other human manipulations have reshaped the forests into an unsustainable condition from the perspective of native species and processes. The HRV in these cases is an envelope of reference conditions that describe the landscape that existed before the pulse of changes associated with Euro-American settlement. For example, the historical range of species distributions or the return interval for disturbance processes may guide their reintroduction over large areas such as within a management plan for a national forest. The HRV in this context has resulted in "let burn" policies for lightning-induced forest fires or policies promoting the reintroduction of disturbance through prescribed fires or prescribed flooding via dam releases. For obvious reasons, modern society chooses not to allow the full reintroduction of natural disturbance: fires are not permitted to burn unchecked and rivers are regulated to prevent floods. In lieu of natural disturbances, anthropogenic disturbances are often advocated as surrogates. For example, the historical range of tree spacing may be used as a guide in fuel reduction treatments, or the historical fir return interval may guide the timing of prescribed fires.

The HRV is also used to emulate natural disturbance regimes with timber harvests. The goal is both ecological and economic. This approach has been applied most often in areas where timber harvests have replaced high-severity fires as the dominant disturbance process such as in boreal and eastern Canada (e.g., Bergeron et al. 2002) and the U.S. Pacific Northwest (e.g., Cissel et al. 1999, Thompson et al. 2006). It rests on the assumption that native forest species have adapted to and depend on a range of disturbance processes such as fire, wind, and flooding. Therefore, the greater the similarity between managed forests and the historical range of conditions, the more likely it is that native species will be sustained (Hunter 1993, Swanson et al. 1994).

Rather than targeting a single historical condition, disturbance-based management seeks to maintain the landscape within its historical range (Swanson et al. 1994). The landscape management plan that is being used in the Blue River Adaptive Management Area in the western Cascades of Oregon is one example of this approach (Cissel et al. 1999): timber harvests are scheduled and designed to mimic the age-class distributions and legacy structures that occurred before fire suppression. Of course, timber harvests are inherently different from natural disturbances and result in distinctive environmental impacts. Therefore, the objective of a disturbance-based approach to silviculture is not exactly to mimic, but rather to incorporate as many attributes of a natural disturbance as possible given the socioeconomic constraints of the harvest. The hope is that organisms will respond to incremental changes toward the HRV, even if major ecosystem components remain outside the HRV.

At least three attributes of natural disturbances can be emulated with forest management (Hunter 1993). First, the frequency of timber harvests can be matched to the expected disturbance interval. Second, silvicultural operations can be designed to leave a legacy stand structure and composition on the site to more closely emulate the forest condition in the aftermath of a disturbance. Third, harvest 
sizes and shapes can mimic the range of expected disturbances. Several other components of a silvicultural prescription could be informed by HRV, e.g., regeneration, site preparation, and spatial distribution, but these have not received much attention in the HRV literature.

\section{Oregon Coast Range: biophysical assessment}

The Pacific Northwest is among the most studied regions in the United States with regard to defining the HRV of ecological conditions and considering the implications of an HRV approach to management. Much of this work has focused on the Oregon Coast Range and has been performed by the Coastal Landscape Analysis and Modeling Study (CLAMS), which is a research cooperative that includes Oregon State University's College of Forestry, the USDA Forest Service Pacific Northwest Research Station, the Oregon Department of Forestry, and the National Commission on Science for Sustainable Forestry. For the past 15 years, CLAMS has focused on analyzing the aggregate ecological, economic, and social consequences of forest policies of different land owners in the Coast Range (Spies and Johnson 2007).

Since European settlement began in the late nineteenth century, the Coast Range has undergone significant changes in forest composition and structure. The modern landscape is a mosaic of ownerships and forest structural classes displaying a mix of different management objectives (Spies et al. 2002). Industrial forestlands comprise the majority of the forested area $(\sim 40 \%)$, followed by nonindustrial private forests and federally managed lands (each approximately 23\%); the smallest ownership class is state forests ( 14\%; Fig. 1). Land tenure explains a significant portion of the variability in forest structure; private industrial lands are associated with young forests, federally managed lands with mature forest cover, and nonindustrial private lands with a wide diversity of cover classes (Stanfield et al. 2002). Regional timber harvest is primarily regulated by market forces; the Oregon Forest Practices Act; State Forest management plans; and federal land management policy, primarily the Northwest Forest Plan. Logging has replaced fire as the prevailing disturbance agent affecting Coast Range forest structure. Virtually all private lands have been harvested at least once since European settlement
(Ohmann and Gregory 2002), and most of the harvest volume comes from clear-cutting (Lettman and Campbell 1997). The timber harvest regime has had great influence on Coast Range forests.

A rich history of HRV research has been done in the Oregon Coast Range, starting with paleoecological reconstructions of the historical fire regime. High-resolution charcoal analysis from Little Lakein the central Coast Range and Taylor Lake in the northern Coast Range show that fire has been the dominant disturbance agent for at least 9000 years (Long et al. 1998). Fires were more frequent, with a mean return interval of $\sim 100-150$ yr from 6500 to $2700 \mathrm{ybp}$ and then shifted to a longer return interval of approximately 200-250 yr, which has been relatively stable for the past 2700 years. A dendrochronological analysis corroborates the fire frequency evidence gleaned from the lake cores and also provides evidence of a highly skewed fire size distribution in which small fires were common, but most acres were burned in large severe fires of between 25 and $75 \mathrm{~km}^{2}$ (Impara 1997). This work also shows a gradient of increasing fire size, severity, and return interval across the Coast Range from east to west, coincident with increasing precipitation. Examinations of general land surveys and other historical records support the notion of high-severity, large, infrequent fires (Teensma et al. 1991, Ripple 1994, Ripple et al. 2000). Studies of old growth forests show that previous stands left a legacy of live and dead trees, resulting in forests with variable tree sizes and canopy layering (Spies et al. 1988, Hanson et al. 1991).

Wimberly et al. (2000) synthesized the historical ecological evidence and used it to build and parameterize a stochastic fire model: the landscape age-class demographics simulator (LADS). LADS examines changes in forest structure resulting from succession and disturbance at a coarse scale ( 9 ha) across a whole region, explicitly recognizing topography, climatic gradients, and fire behavior. By running LADS for thousands of simulated years, Wimberly et al. (2000) estimated the bounds around the HRV of old forest structure. At the late successional reserve scale $(\sim 40,000 \mathrm{ha})$, the HRV of old forest was between 0 and $100 \%$, which is not a particularly useful estimate. However, after scaling up to the regional scale (approximately two million hectares), the long fire return interval produced a landscape typically occupied by between 25 and $75 \%$ old forests (> 200 years) in variably sized patches often larger than 100,000 ha. 
Fig. 1. The ownership mosaic of the Oregon Coast Range.

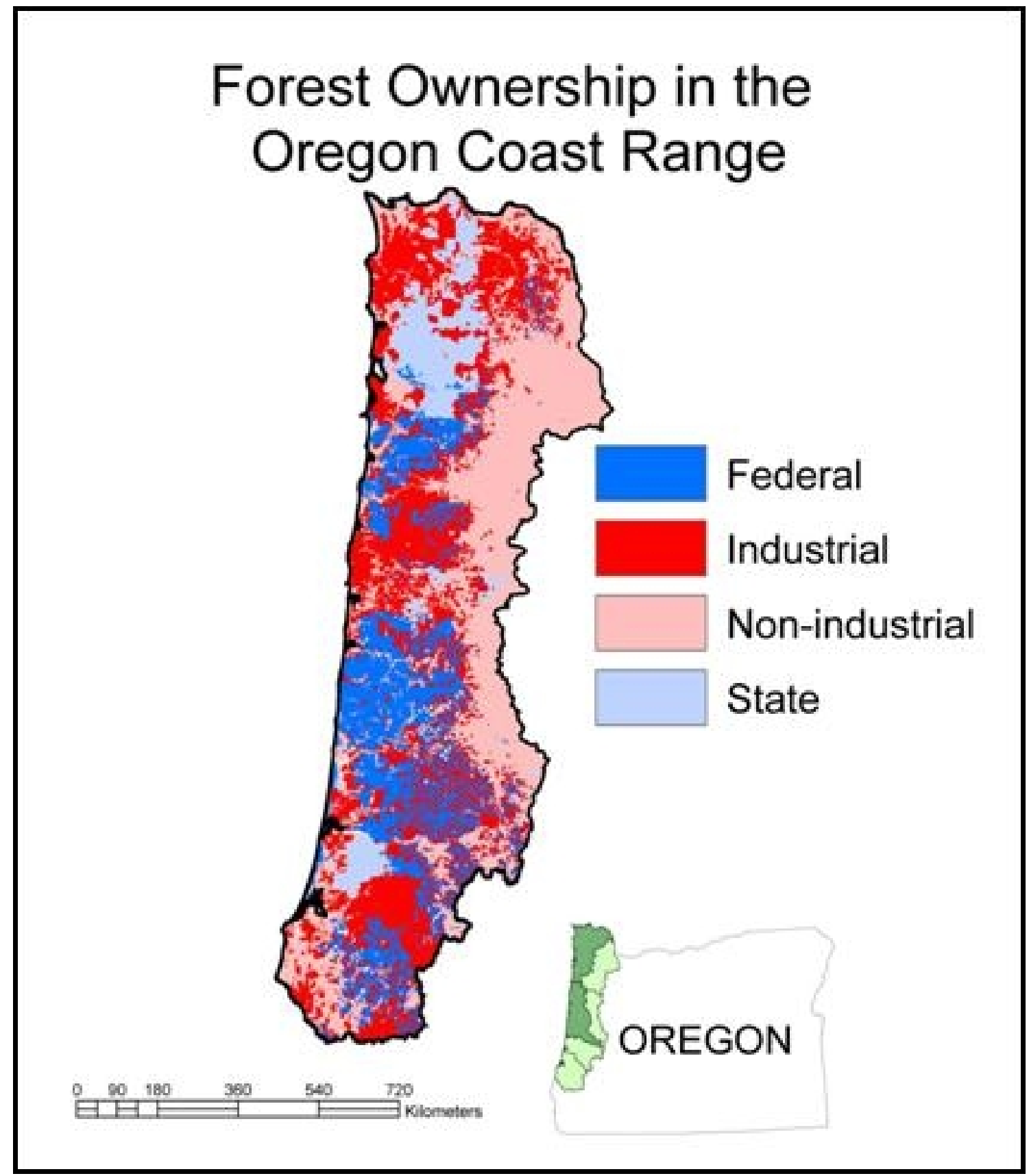


They concluded that when measured at the provincial scale, the Coast Range is well outside of the HRV with regard to the amount of old-growth forest. This work underscores the importance of considering the spatial scale at which the HRV is relevant and useful.

Wimberly (2002) refined LADS to incorporate more complex successional pathways and to model the HRV of Coast Range forests in four different age-classes and as it relates to several landscape metrics. Nonaka and Spies (2005) refined LADS further to characterize seven age classes, including very young and very old, and conducted a spatial analysis of the full range of metrics offered by FRAGSTATS (McGarigal and Marks 1995) to estimate the degree of departure of the current landscape from the HRV. Both studies concluded that the modern landscape structure was well outside the HRV, mostly because of the abundance of young compared to old forest. In a related study, Nonaka et al. (2007) retrofitted LADS with a network of permanent forest plot data to examine the HRV of live and dead woody biomass, showing that the HRV could be estimated for more than landscape pattern and structural stages. They conclude that the modern landscape is also outside the HRV in terms of these important structural components.

\section{Oregon Coast Range: social assessment}

Even if the landscape were capable of supporting the HRV, there may not be social permission to do so. Most landscapes in the United States are well outside the HRV by many important measures. It follows, therefore, that there will need to be radical changes in management if an HRV approach is used. Some of the changes are sure to disrupt people's sensibilities and livelihoods. For example, the reintroduction of fire is a common component in HRV conservation, but fire has inherent risks related to air quality, property damage, and aesthetics. Furthermore, not all fires were of the type idealized by low-severity surface fires in ponderosa pine forests, as the natural, high-severity Yellowstone fires attested.

Land tenure often dictates the ecological status of the landscape (e.g., Stanfield et al. 2002). How can the HRV be superimposed over the ownership mosaic? Different policies and objectives determine the management strategies on each property. Public lands may be large enough to accommodate HRV conservation, but private landowners are often unwilling or unable to collaborate across the spatial scale necessary to accomplish HRV objectives (Thompson et al. 2004). Even if the range of owner objectives can be fit to an HRV strategy, the static property boundaries will surely conflict with the shifting mosaic of ecological conditions that resulted from most historical disturbance regimes.

If the HRV is used to govern timber harvest, there may be economic consequences, which are difficult to overcome (Adamowicz and Veeman 1998). For example, emulating disturbance regimes with timber harvests in regions with high-severity-lowfrequency fire regimes may mean fewer but larger timber harvests. If this is set as policy, landowners will likely object to a reduction in the allowable cut, the public will object to the poor aesthetics associated with large timber harvests, and equitably distributing a limited number of harvests across ownerships will be challenging, to say the least.

The social assessment for the FRV project was completed by analyzing data transcribed from a half-day focus group that addressed a series of questions concerning HRV and FRV and alternative strategies for conserving biodiversity. Specific questions included: How do social factors such as land use and development affect the ranges of variability that can be used when managing for biodiversity? How will biophysical factors such as climate change and invasive species influence the way that ranges of variability are used to manage biodiversity? What future strategies incorporating both social and biophysical ranges might be most successful in conserving biodiversity?

The data were recorded and transcribed by a court reporter and then analyzed in relation to the research question: How do future trends affect the usefulness of the HRV concept? The 15 workshop attendees included managers from public and private lands, nongovernmental organization representatives, federal and state researchers, a watershed council coordinator, and an extension forestry consultant to private landowners. The analysis identified three key themes. First, the HRV is best used as a tool, not a target. Second, the spatial scale and ownership objectives variably constrain the use of the HRV. Third, centralized or single-focus management is a poor fit for dynamic systems. 


\section{The HRV is a tool, not a target}

The participants thought that the HRV is best used as a tool, rather than a target, i.e., as part of the planning process that helps land managers understand the environmental context in which they are making their decisions. Among the many specific decision-making actions for which it was considered useful, participants mentioned managing options, identifying risk, considering short- and long-term implications, quantifying native species, learning about systems and their performance, and identifying the "envelope of future possibilities."

Pragmatism was a key element of the discussion about how the HRV might be used. A geographer compared its use to managing a retirement portfolio: "Do we ignore the past? Of course we do not ignore the past. Do we think that the past is a perfect predictor of the future? No, of course we do not think that."

Indeed, it was when cast as a target, an arbitrary point in time in the past that represented a mere snapshot of past conditions that might be mimicked or successfully reproduced, that the HRV evoked the greatest anxiety among land managers. A state lands manager noted: "As we talk about recovery, our assumption is that we are going to recover back to what we had in the past. And that basic value that we have in our language is probably flawed." At the conclusion of the workshop, a private land manager characterized the whole discussion as positive because it was "tending to go toward reality instead of some artificial thing, some snippet of time." A federal land manager added that to focus on the HRV concept as a template was to miss its value as a means by which to learn about the variability in system performance.

The importance of the HRV, it was generally agreed, lies more in its invoking past processes and systems than past conditions. Understanding processes helps one to understand how they might best be bolstered under current and future conditions. The range component of the HRV also encourages one to consider a suite of possible outcomes of management, whereas 20 years ago, it was more typical to pursue single goals or outcomes.

A fish biologist noted that if we understood fully the processes that governed past landscapes and their highly variable outcomes through time, we might escape our constant "illusions of failure" as we attempt to manage watersheds for salmon habitat. Disturbance effects are very real: there were not always perfect habitat conditions across the landscape. In this vein, a watershed council coordinator anticipated the use of specific HRVderived data formats: "It would be so valuable to have a reasonable understanding of historical vegetation versus alterations due to land use, in GIS coverage that is accurate enough to compare to current vegetation and land use, and then be able to consider the future trends and restoration possibilities."

The related value of recognizing resilience among the forest components is a key factor in understanding landscape sustainability. The HRV itself, then, is not to be seen as an objective; instead, it was recognized, perhaps more openly than in any other region, as a concept whose contribution is best grasped as a coarse-filter framework for imagining possible futures. It is not the only or even always the best means of designing landscapes. And it must be supported by monitoring: "Without it, we are looking back at just what we speculate and what somebody has experienced that the past was like."

An extension forester with long-term experience in working with farmers and private nonindustrial foresters noted that the greatest barrier to the use of HRV is the pace of social change: "The world we live in is changing so rapidly and people are pressured from so many different sides that it almost renders this idea of the historical range of variability somewhat irrelevant." A research ecologist supported this viewpoint: "It is clear that you take this idealized theoretical HRV notion from academics and move it into the real world and it does not go very far. But from our experience, you can find elements that people are willing to work with."

Participants noted that there may be more room to experiment with ideas such as the HRV on larger tracts of land, particularly those that are publicly owned, than on smaller ownerships with multiple objectives.

\section{Spatial scale and ownership objectives variably constrain the use of the HRV}

The group's discussions suggested that both scale and ownership directly affect the degree to which the HRV "makes sense" on any tract of land, which in turn will affect whether collaboration can occur 
across ownerships using either principles of the HRV, or considerations for the FRV. In general, the larger the ownership tract, the more likely it is for managers to consider and apply historical variability in their planning. State and federal land managers already actively consider the HRV in planning, and these are the land managers that are most likely to interact with ecologists to derive information about historical ranges of variability.

Small landowners or large private owners more frequently design land uses around economic objectives, whether for intensive or occasional timber management or farming practices. Nonetheless, the value of the HRV in understanding how processes work across the landscape still suggests considering how to capture such knowledge in policy. A landscape geographer noted: "One pragmatic way would be to identify those common sets of landowner mandates in an attempt to define from that group's perspective what the plausible political sideboards of the future are with an eye to what the short range of variability has been on the lands that that group of owners control."

Shorter time frames may be one part of an approach for small landowners, as may a new framework for experimentation by landowners. However, the overall challenge is the host of different owner objectives spread across the landscape, from timber to residential values, land exchanges, and solely ecological goals. Among these, objectives can compete and conflict within one ownership, e.g., the capital-improvement basis of the roads system on state lands, which directly interferes with historical and present ecosystem functions and processes.

The huge changes represented by human development on the landscape were noted as already outside the range of historical variability. This generated questions that were not fully answered about whether humans need to be regarded as a disturbance force in their own right. Land-use changes are an integral part of the social range of variability (SRV) expressed through time across landscapes and are a key factor in determining future management choices.

The very variability of nature's expression across the landscape was also noted to be a potential source of win-win outcomes: look at natural variability, look at ownership variability, and see where they line up to afford creative management opportunities.
One example cited was planting marketable hardwoods because they appear to be a vegetation type that is declining to below historical ranges.

A policy and management challenge that emerged briefly during the workshop was the different science/management conception of biodiversity. Scientists general classify it as a hierarchical, circular matter; managers look at it more simply as a matter of considerable controversy that is best not referred to explicitly in management discussions.

Centralized, single-focus management is a poor fit for dynamic systems

This theme was considerably less cohesive than the other two, but the idea of the serious need for alternative "integrationist" approaches to weaving sociopolitical and ecological knowledge into more flexible, future-oriented forms of management was expressed in a variety of ways. The extension forester noted that we have until relatively recently been accustomed to viewing nature as something to be controlled for our own purposes. Today's efforts to understand nature and its systems and processes support the idea of multiple potential pathways of natural landscape development: "an envelope of possibilities in the future forest conditions from no forest to forest everywhere to totally urban," according to a research ecologist. Participants agreed that ecologists working at the landscape scale must try to convey this comprehensive view of landscapes beyond their immediate peers, moving it from "shelf science" into the decisionmaking arena.

Grasping the concept of dynamic landscapes generates a number of changes in how one views land management and ownership. First, the engagement and learning of landowners is a critical piece of the biodiversity puzzle, according to a research forester, and will directly affect levels of acceptability for management activities. Other participants added that the puzzle also requires maintaining future options, leaving room for experimentation both within and across ownerships, and conscientiously gathering monitoring data.

Second, humans are increasingly becoming significant agents of change in the landscape. The rate of change in markets, policies, and scientific discoveries, with effects from climate, development, and changing ownership, is setting a fast pace for the world. It is not just a dynamic ecological 
landscape that faces us, it is a dynamic cultural landscape as well. We do not know what the physical landscape or the social landscape will be like in 10,50 , or 100 years. One participant stated, "I'm wondering if there is some way to integrate those pathways, the social pathways and ecological pathways, so that we are not constraining one to bind the other, but we are seeing where they might lead us."

A fish biologist observed that we are prone to "an idealized view of how the world works" that all too easily blocks our ability to recognize landscape change as inevitable, even when it is as dramatic and apparently damaging as a debris flow, for example. Social change can be similarly difficult to accept, but the mutability of cultural preferences and social acceptability is already apparent in a number of ways. The perception of fire is one of the examples provided by participants. We are in a "post Smokey the Bear" era, which should remind us of the dynamic nature of the SRV. Public perceptions can and do change. A research forester noted that ideas about the HRV could make the same transition: "History is relevant to perception, policy, and practice. It seems to me where we are in the [Oregon] Coast Range, or maybe western Oregon in general, is that we need to work on public perception: the understanding of the nature of change and our role in it, past and future."

The third change is the search for political plausibility. It has not been customary for ecologists to have to consider the effects of social acceptability on the meaning of their work, but the political horizon for science has changed. A watershed coordinator lamented, "I do not believe that the watershed community that I live and work in has any real grasp of the importance of natural variability or the effect that we have on climate or how climate change will effect us, and most of all what can be done by us to reverse the trend or lessen the blow to humans and most of all to the rest of the natural world."

Several participants noted what they saw as the past folly of believing that the desired future condition could lead to one particular outcome rather than numerous possibilities. In this context, adaptive management was mentioned by a number of participants, who each articulated in their own way, the importance of a flexible approach to working with dynamic landscapes, both social and ecological.

\section{Future range of variability}

Given that the Oregon Coast Range has welldeveloped estimates of the HRV of the landscape structure and that timber harvest has replaced large severe fires as the dominant disturbance, it is a good candidate to examine the FRV in light of the HRV. At least two studies have modeled future Coast Range forests and compared them to the HRV. Nonaka and Spies (2005) used LADS to examine what might happen if timber harvesting ceased and the historical fire regime was reintroduced. Surprisingly, their analysis showed that the unchecked fire would, at first, move the landscape away from the HRV. This was because fire would likely burn some old growth forests, which are well below the HRV and are slow to restore to historical levels. They anticipate that it would take many centuries before the current ownership pattern would disappear and the landscape would return to the HRV, as defined by a full suite of landscape metrics.

In a related study, Thompson et al. (2006) used information on the Coast Range's historical fire regime as a reference to develop and simulate some of the ecological and economic effects of disturbance-based policies. They used the landscape analysis and management simulator (LAMPS; Bettenger and Lennette 2004) to project landscape conditions, forest dynamics, management activities such as clear-cutting and thinning, and harvest volumes over the next century. Their simulations included projections of human population growth and land development. LAMPS was used to simulate changes in the Oregon Forest Practices Act (OFPA) that would encourage private-land timber owners to conduct harvests that would more closely resemble historical disturbance process (Table 1). The vast majority of timber harvests in the region are governed by the OFPA. Fire severity was emulated by escalating the greentree retention standards far beyond current levels. Fire frequency was emulated by matching the annual harvestable area to the average natural fire rotation. Fire extent was emulated by increasing the harvest-unit size regulations to 10 times the average modern clear-cut size.

Simulated disturbance-based policies produced age-class distributions more similar to the HRV than those created by current policies. The proportions of early seral and young forest were within the historical range within $100 \mathrm{yr}$. It should be noted, 
Table 1. A description of policy changes used to emulate the historical disturbance regime of the Oregon Coast Range. Source: Thompson et al. (2006).

\begin{tabular}{|c|c|c|c|}
\hline $\begin{array}{l}\text { Attribute of the fire } \\
\text { regime }\end{array}$ & Method of emulation & $\mathrm{OFPA} \dagger$ & Disturbance-based policy \\
\hline Severity & Legacy structure & $\begin{array}{l}\text { Five snags or green trees }>28 \\
\text { cm DBH } \$ \text { plus } 1.5 \mathrm{~m}^{3} \text { of } \\
\text { downed wood per hectare }\end{array}$ & $\begin{array}{c}\text { Interior climate zone: } 40 \% \text { of trees in } \\
\text { clumps plus } 12 \text { green trees }>60 \mathrm{~cm} \mathrm{DBH} \\
\text { retained per hectare; } \\
\text { Coastal climate zone: } 10 \% \text { of trees in } \\
\text { clumps plus } 12 \text { green trees }>60 \mathrm{~cm} \mathrm{DBH} \\
\text { retained per hectare }\end{array}$ \\
\hline Frequency & $\begin{array}{c}\text { Annual allowable } \\
\text { harvest }\end{array}$ & $\begin{array}{l}\text { Five-year wait between } \\
\text { adjacent clear-cuts limits } \\
\text { harvests indirectly }\end{array}$ & $\begin{array}{l}\text { Interior climate zone: } 5 \% \text { of zone harvested } \\
\text { each } 10-\mathrm{yr} \text { period; } \\
\text { Coastal climate zone: } 10 \% \text { of zone } \\
\text { harvested each } 10-\mathrm{yr} \text { period; } \\
\text { OFPA adjacency rules apply }\end{array}$ \\
\hline Extent & Clear-cut size limit & Clear-cut size limit of 48 ha & $\begin{array}{l}\text { Industrial clear-cut size limit of } 250 \mathrm{ha} \text {; } \\
\text { Nonindustrial private clear-cut size limit } \leq \\
48 \mathrm{ha}\end{array}$ \\
\hline
\end{tabular}

$\dagger$ Oregon Forest Practices Act.

$\ddagger$ Diameter at breast height.

however, that there are large differences between modern young plantations and the natural young forests that existed historically. Within this timeframe, older forests moved closer to but were still below historical conditions. Interestingly, under the disturbance-based policy structure, patch size distributions were less similar to historical conditions (Fig. 2). This was because, even after a 10 -fold increase in the average harvest size, the clear-cut size limit remained well below the average historical fire size, and the ownership pattern divided areas of young and old forests.

With regard to economic indicators, in the short term, the annual revenue produced by the disturbance-based policies was estimated to be 20$60 \%$ lower than that produced by the current policy. However, the relative costs declined significantly through time. This reflected the degree of departure between the modern and historical disturbance regimes. Thompson et al. (2006) hypothesized that policies that attempt to reproduce historical conditions in the Coast Range will require federal forests to provide large patches of old forest that were common in the historical landscape. Using public lands for this purpose would dampen costs to private landowners, who would continue to harvest and to provide young and early seral forest structure, which were also historically abundant. In addition, this experiment illustrates the difficulty of meeting regional-scale conservation goals across multiple private lands and suggests that distributing the costs and benefits equitably across large landscapes could be a significant challenge.

\section{DISCUSSION AND CONCLUSIONS}

There is often a tacit assumption that modern landscapes remain capable of supporting the HRV of forest conditions. This may be a specious assumption for several reasons, some biophysical and some social. The first biophysical hurdle, climate change, may well be insurmountable. The modern and future climate may not support the range of species that existed historically. This may be a direct effect such as when temperature increases supplant existing communities in favor of southern 
Fig. 2. One-hundred-year simulations of forest growth and management using (A) current policy and (B) a disturbance-based approach using the HRV as a reference. There is a greater distinction of age classes along the square ownership blocks separating private and public lands under the current policy scenario than under the disturbance-based approach.
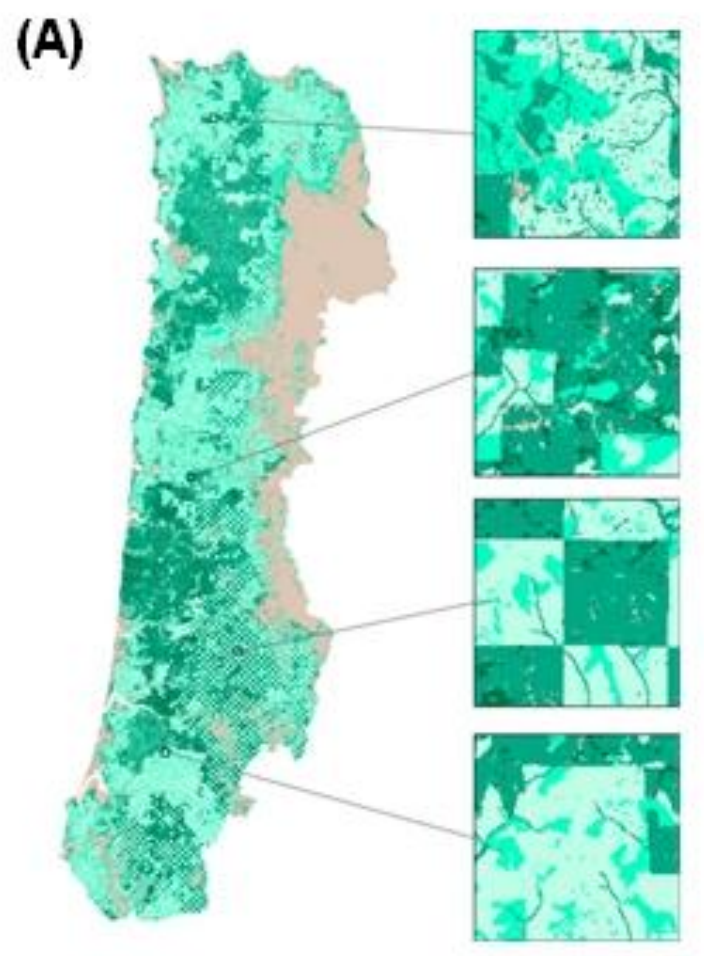

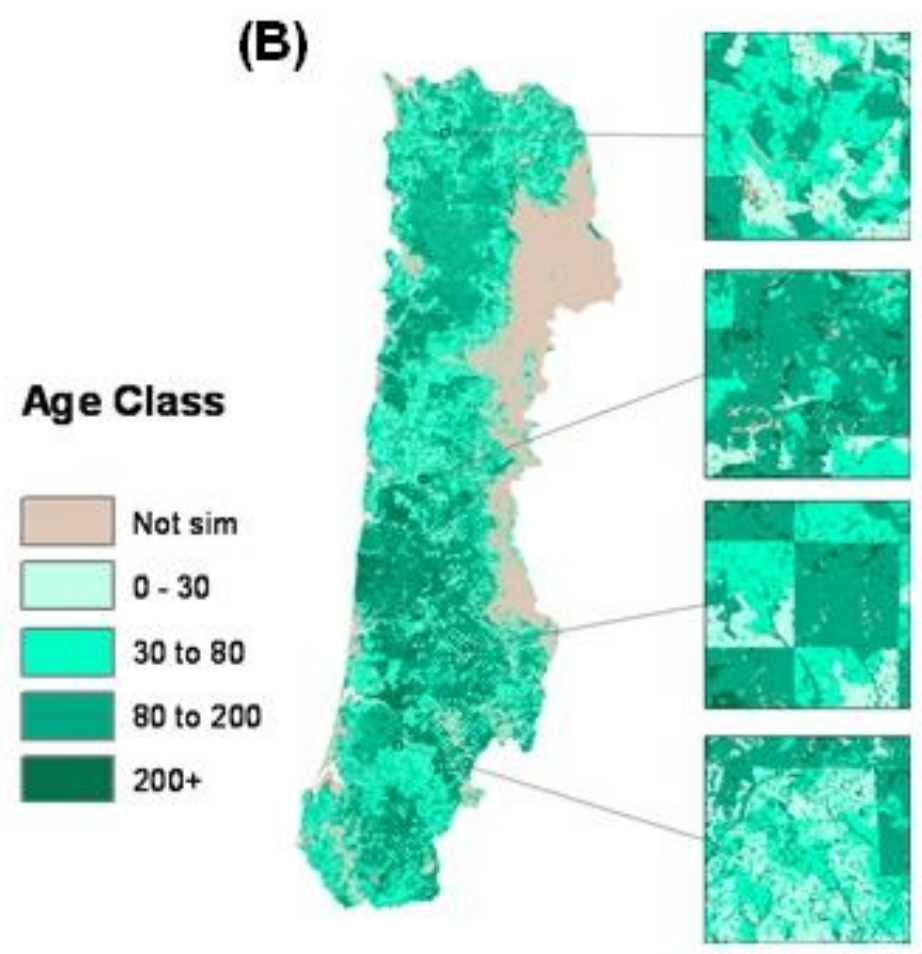

communities. Or, climate effects may be indirect by changing the disturbance regime to one that does not support the historical species assemblages. How then can managers use past landscape conditions as a reference for the future?

A second hurdle to using historical landscapes as a reference condition is land development, which has reduced the total forested land base and fragmented what remains, probably eliminating the option of allowing wildfires to burn unchecked. Furthermore, historical patterns may be impossible to re-create on landscapes with low permeability, small patch sizes, and unprecedented amounts of edge habitat. Continued human population growth and recent changes to land-use planning rules promise to exacerbate the problem, bringing with them variations in how the spectrum of ecological conditions, and thus of management activities, will be accepted. Exotic species, particularly invasive exotics and exotic pathogens, may also stymie the recreation of historical species assemblages and change future disturbance regimes. Exotic species combined with climate change and land development may have synergistic effects that produce unprecedented conditions and pathways that we have not yet considered.

The idea emerged strongly from the social data that the HRV is a single tool in what landowners and managers see as a large, but still often inadequate, toolbox. In the face of ongoing and increasingly rapid change, pinning hopes to one scientific idea of how to manage is unlikely to yield usable results across a broad swath of society, particularly if it is labeled as a target or a way to find the correct 
reference point in time to guide management. It is limited by scale, ownership objectives, research into its own components, and variable understanding of what it means or might lead us to do. Nonetheless, it may very well continue to have value as a framework for considering various options under changing conditions.

As for social and ecological integration, a great number of mismatches and different ways of thinking will likely continue to stand in the path of integration for some time. The distance that we have moved from the HRV, and the highly dynamic nature of social desires and the SRV that they ultimately influence, mean that management by the FRV will be no easy task. The enterprise demands that we simultaneously learn new languages and cultures and grapple with both social and ecological complexity. For example, Berkes (2004:623) notes the example of the scale challenge: "One of the insights from complexity thinking is that a multiplicity of scales prevents there being one 'correct' perspective in a complex system: Phenomena at each level of the scale tend to have their own emergent properties. The system must be analyzed simultaneously at different scales."

What are the alternatives to providing the habitat conditions that once supported the suite of native species we now wish to protect? We could use single-species approaches like the Endangered Species Act and/or viability analysis. However, this seems unrealistic given the sheer number of species, how little we know about them, and how past policies based on single-species management have failed. We can try static management, as in the National Park system, where we choose one condition and try to maintain it indefinitely, but this approach denies all that has been learned about dynamic ecosystems and ignores the diverse objectives of the owners. Or, we can try creating unprecedented conditions that seem congruent with our forecasts of the future. Is this the FRV approach to conservation?

What seems evident is that if we explicitly require an integrationist approach to biodiversity conservation, we can recognize that it will necessarily be multifaceted and in many ways incomplete. Findings from the social assessment suggest that the pace of both social and ecological change, combined with the increasing ability of humans to change their ecological environment, require that we continue to think through biodiversity conservation and make adjustments for the foreseeable future. It is not a one-time task. The development of the FRV will constitute an ongoing negotiation process.

Responses to this article can be read online at: http://www.ecologyandsociety.org/voll4/iss 1/art18/ responses/

\section{Acknowledgments:}

This research was funded by the National Commission on Science for Sustainable Forestry. We thank the participants in the Oregon FRV social assessment for their time and thoughtful comments.

\section{LITERATURE CITED}

Adamowicz, W. L., and T. S. Veeman. 1998. Forest policy and the environment: changing paradigms. Canadian Public Policy 2:50-61.

Aplet, G. H., and W. S. Keeton. 1999. Application of historical range of variability concepts to biodiversity conservation. Pages 71-86 in R. K. Baydack, H. Campa, and J. B. Haufler, editors. Practical approaches to the conservation of biological diversity. Island Press, Washington, D. C., USA.

Bergeron, Y., A. Leduc, B. D. Harvey, and S. Gauthier. 2002. Natural fire regime: a guide for sustainable management of the Canadian boreal forest. Silva Fennica 36:81-95.

Berkes, F. 2004. Rethinking community-based conservation. Conservation Biology 18(3):621-630.

Bettinger, P., and M. Lennette. 2004. Landscape management policy simulator (LAMPS), version 1.1 user's guide. Oregon State University, Corvallis, Oregon, USA.

Botkin, D. B. 1992. Discordant harmonies: a new ecology for the 21st century. Oxford University Press, Oxford, UK.

Botkin, D. B. 1996. Adjusting law to nature's discordant harmonies. Duke Environmental Law and Policy Forum 7:25-37. 
Cissel, J. H., F. J. Swanson, and P. J. Weisberg. 1999. Landscape management using historical fire regimes: Blue River, Oregon. Ecological Applications 9:1217-1231.

Clawson, M. 1984. Major alternatives for future management of federal lands. Pages 195-234 in S. Brubaker, editor. Rethinking the federal lands. Johns Hopkins University Press, Baltimore, Maryland, USA.

Duncan, S. L. 2006. Mapping whose reality? Geographic information systems (GIS) and "wild science." Public Understanding of Science $\mathbf{1 5}$ (4):411-434.

Firey, W. 1960. Man, mind, and land: a theory of resource use. Free Press, Glencoe, Illinois, USA.

Fischer, F. 2000. Citizens, experts, and the environment: the politics of local knowledge. Duke University Press, Durham, North Carolina, USA.

Franklin, J. F., and R. T. T. Forman. 1987. Creating landscape patterns by forest cutting: ecological consequences and principles. Landscape Ecology 1:5-18.

Hansen, A. J., T. A. Spies, F. J. Swanson, and J. L. Ohmann. 1991. Conserving biodiversity in managed forests. Bioscience 41:382-392.

Hunter, M. 1990. Wildlife, forests, and forestry. Prentice Hall, Englewood Cliffs, New Jersey, USA.

Hunter, M. 1993. Natural fire regimes as spatial models for managing boreal forests. Biological Conservation 65:115-120.

Impara, P. C. 1997. Spatial and temporal patterns of fire in the forests of the central Oregon Coast Range. Oregon State University Press, Corvallis, Oregon, USA.

Landres, P. B., P. Morgan, and F. J. Swanson. 1999. Overview of the use of natural variability concepts in managing ecological systems. Ecological Applications 9:1179-1188.

Lettman, G. J., and D. Campbell. 1997. Timber harvesting practices on private forest land in western Oregon. Oregon Department of Forestry, Salem, Oregon, USA.
Long, C. J., C. Whitlock, P. J. Bartlein, and S. H. Millspaugh. 1998. A 9000-year fire history from the Oregon Coast Range, based on a high-resolution charcoal study. Canadian Journal of Forest Research 28:774-787.

McGarigal, K., and B. Marks. 1995. FRAGSTATS: spatial pattern analysis program for quantifying landscape structure. General Technical Report PNW-GTR-351, USDA Forest Service, Pacific Northwest Research Station, Portland, Oregon, USA.

Morgan, P., G. Aplet, J. Haufler, H. Humphries, M. Moore, and W. Wilson. 1994. Historical range of variability: a useful tool for evaluating ecosystem change. Journal of Sustainable Forestry 8:87-112.

Nonaka, E., and T.A. Spies. 2005. Historical range of variability in landscape structure: a simulation study in Oregon, USA. Ecological Applications 15:1727-1746.

Nonaka, E., T. A. Spies, M. C. Wimberly, and J. L. Ohmann. 2007. Historical range of variability in live and dead wood biomass: a regional-scale simulation study. Canadian Journal of Forest Research 37(11):2349-2364.

Ohmann, J. L., and M. J. Gregory. 2002. Predictive mapping of forest composition and structure with direct gradient analysis and nearestneighbor imputation in coastal Oregon, USA. Canadian Journal of Forest Research 32:725-741.

Pouyat, R. V. 1999. Science and environmental policy-making them compatible. BioScience 49 (4):281-287.

Priest, S. H. 1995. Information equity, public understanding of science, and the biotechnology debate. Journal of Communication 45(1):39-54.

Ripple, W. J. 1994. Historic spatial patterns of old forests in western Oregon. Journal of Forestry 92:45-49.

Ripple, W. J., K. T. Hershey, and R. G. Anthony. 2000. Historical forest patterns of Oregon's central Coast Range. Biological Conservation 93:127-133.

Rykiel, E. J. 2001. Scientific objectivity, value systems, and policymaking. BioScience $\mathbf{5 1}$ (6):433-436. 
Spies, T. A., J. F. Franklin, and T. B. Thomas. 1988. Coarse woody debris on Douglas-fir forest of western Oregon and Washington. Ecology 69:1689-1702.

Spies, T. A., D. E. Hibbs, J. L. Ohmann, G. H. Reeves, R. J. Pabst, F. J. Swanson, C. Whitlock, J. G. Jones, B. C. Wemple, W. Perendes, and B. Schrader. 2002. The ecological basis for forest ecosystem management in the Oregon Coast Range. Pages 31-67 in S. D. Hobbs, J. P. Hayes, R. L. Johnson, G. H. Reeves, T. A. Spies, J. C. Tappeiner, and G. Wells, editors. Forest and stream management in the Oregon Coast Range. Oregon State University Press, Corvallis, Oregon, USA.

Spies, T. A., and K. N. Johnson. 2007. Projecting forest policy and management effects across ownerships in coastal Oregon. Ecological Applications 17(1):3-4.

Stanfield, B. J., J. C. Bliss, and T. A. Spies. 2002. Land ownership and landscape structure: a spatial analysis of sixty-six Oregon (USA) Coast Range watersheds. Landscape Ecology 17:685-697.

Stankey, G. H., and B. Shindler. 2006. Formation of social acceptability judgments and their implications for management of rare and littleknown species. Conservation Biology 20(1):28-37.

Swanson, F. J., J. A. Jones, D. O. Wallin, and J. H. Cissel. 1994. Natural variabilty-implications for ecosystem management. Pages 80-94 in M. E. Jensen and P. S. Bourgeron, editors. Eastside forest ecosystem health assessment volume II, ecosystem management: principles and applications. USDA Pacific Northwest Research Station, Portland, Oregon, USA.

Swetnam, T. W., C. D. Allen, and J. L. Betancourt. 1999. Applied historical ecology: using the past to manage for the future. Ecological Applications 9:1189-1206.

Teensma, P., J. T. Rienstra, and M. A. Yeite. 1991. Preliminary reconstruction and analysis of change in forest stand age classes of the Oregon Coast Range from 1850 to 1940. Technical Note T/N OR-9. USDI Bureau of Land Management, Portland, Oregon, USA.

Thompson, J. R., M. D. Anderson, and K. N. Johnson. 2004. Ecosystem management across ownerships: the potential for collision with antitrust laws. Conservation Biology 18:1475-1481.

Thompson, J. R., K. N. Johnson, M. Lennette, T. A. Spies, and P. Bettinger. 2006. Historical disturbance regimes as a reference for forest policy in a multi-owner province: a simulation experiment. Canadian Journal of Forest Research 36:401-417.

Wimberly, M. C. 2002. Spatial simulation of historical landscape patterns in coastal forests of the Pacific Northwest. Canadian Journal of Forest Research 32:1316-1328.

Wimberly, M. C., T. A. Spies, C. J. Long, and C. Whitlock. 2000. Simulating historical variability in the amount of old forests in the Oregon Coast Range. Conservation Biology 14:167-180.

Yosie, T. 2001. Science-based decision making at the crossroads. Vital Speeches of the Day 67 (7):216-220. 